\title{
O Assistente Social como trabalhador na Política de Assistência Social
}

\author{
The social worker as a worker in the Social Assistance Policy
}

\begin{abstract}
Elisa Maria Brisola *
\section{Resumo:}

O presente artigo objetiva refletir sobre a realidade profissional do assistente social como trabalhador na política de assistência social. Analisa as mudanças operadas na política sociais públicas, sobretudo na Assistência Social, inserida no campo tensionado da Seguridade Social em tempos de reação conservadora e crise do capital. Aponta os desafios postos aos profissionais e indica possibilidades de resistência junto aos demais trabalhadores. $\mathrm{O}$ artigo é parte da pesquisa financiada pelo CNPq, realizada na Região Metropolitana do Vale do Paraíba no período de 2011-2014 com assistentes sociais que atuam no Sistema Único de Assistência Social (SUAS). Os profissionais das instituições públicas e privadas, de municípios de todos os Portes estabelecidos na Política Nacional de Assistência Social foram entrevistados a partir de um roteiro de questões afetas ao trabalho profissional.
\end{abstract}

Palavras-chave: Assistente social. Trabalho profissional. Políticas sociais.

\begin{abstract}
:
This article aims to reflect on the professional reality of the social worker as a worker in social welfare policy. Analyzes the changes operated on public social policy, especially in Social Assistance, part of the tensioned field of Social Security in conservative reaction times and capital crisis. Points out the challenges posed to professionals and indicates possibilities of resistance together with the other workers. The article is part of research funded by CNPq, held in the Paraiba Valley metropolitan region in the 2011-2014 period with social workers who work in the Unified Social Assistance (SUAS). The professionals of public and private institutions, municipalities of all Portes established in the National Social Assistance Policy were interviewed from a script questions related to professional work.
\end{abstract}

Keywords: Social worker. Professional work. Social policies.

\section{Introdução}

Esse texto retrata os achados da pesquisa realizada entre 2011-2014 sobre o trabalho do assistente social no Sistema Único de Assistência Social (SUAS) desenvolvida na região Metropolitana do Vale do Paraíba- SP. A pesquisa objetivou identificar as dificuldades do exercício profissional do Assistente Social no SUAS e as estratégias individuais e coletivas construídas para sua superação; buscou também

\footnotetext{
* Universidade de Taubaté. Assistente Social; Mestre (1996) e Doutora (2003) em Serviço Social pela Pontifícia Universidade Católica de São Paulo. E-mail: elisabrisola@gmail.com
} 
conhecer as formas de resistência dos profissionais frente aos rumos neoliberais tomados na administração pública, na perspectiva de privatização do SUAS.

Antes mesmo de adentrar no debate acerca do trabalho do assistente social, importa reportar-nos ao contexto contemporâneo de crise do capital. Essa crise desenrola-se desde os anos de 1970. Trata-se de uma crise estrutural "que expõe as contradições da dinâmica da acumulação, manifestando-se em diversas frentes: a financeira, a ambiental, a urbana e a do emprego" (MOTA, 2010, p. 13), dentre outras.

$\mathrm{Na}$ análise criteriosa de Mészáros (2002), trata-se de uma crise de longa duração, de caráter global, de alcance mundial, sem saídas a curta ou longo prazo. Nesse sentido, visando recompor os patamares de acumulação o capital engendra uma série de estratégias, algumas delas amplamente estudadas por autores como Mészáros - o metabolismo do capital (2002); Antunes - as metamorfoses e a perda do sentido do trabalho (2005); Harvey - a acumulação flexível (2003); Mandel - o capitalismo tardio (1990), dentre outros.

As estratégias de recomposição do capital em seu conjunto afetam a vida e o trabalho dos trabalhadores aprofundando e redimensionando os processos econômicos e políticos com a globalização e financeirização da economia, a reestruturação produtiva e o neoliberalismo, produzindo mudanças culturais e ideológicas, dentre outras.

As mudanças forjadas pelo capital no escopo da crise de acumulação do último quartel do século XX trouxeram, segundo Thébaud-Mony e Druck (2007, p. 25), "uma nova conjuntura histórica, dando conteúdo a um novo modelo de trabalho e vida" (grifos dos autores).

Os processos de externalização, precarização e flexibilização como estratégias integrantes do capitalismo mundializado, afetam os trabalhadores de diferentes países, ainda que com particularidades, dadas as condições históricas de cada um (THÉBAUD-MONY; DRUCK, 2007).

Nesse sentido, o processo de precarização:

[...] compreendido como processo social constituído pela amplificação e institucionalização da instabilidade e da insegurança, expressa nas novas formas de organização do trabalho - onde a terceirização/subcontratação ocupa um lugar central - e no recuo do papel do Estado como regulador do mercado de trabalho e da proteção social através das inovações da 
legislação do trabalho e previdenciária. Um processo que atinge todos os trabalhadores, independente de seu estatuto, e que tem levado a crescente degradação das condições de trabalho, saúde (e de vida), dos trabalhadores e da vitalidade da ação sindical (THÉBAUD-MONY; DRUCK, 2007, p. 31).

István Meszáros (2007, p.148) explica que os verdadeiros obstáculos confrontados pelo trabalho na contemporaneidade podem ser resumidos em duas palavras: "flexibilidade" e "desregulamentação" às quais equivalem à "implacável precarização da força de trabalho" (grifos do autor). Para o autor, tais perspectivas carregam "agressivas inspirações" anti-trabalho e políticas neoliberais.

Nesse contexto, as mudanças na dinâmica do capitalismo orientam-se por uma perspectiva de classe revelando-se como uma ofensiva do capital contra o trabalho assalariado (ALENCAR; GRANEMANN, 2009).

$\mathrm{Na}$ América Latina, esses processos ganham contornos ainda mais perversos tendo em conta as condições precárias de grande parte dos trabalhadores, os quais se encontram desprotegidos, seja por sua inserção no mercado informal, seja pelas mudanças operadas nas relações de trabalho. No caso brasileiro, tais processos são favorecidos pela ausência de regulação do Estado e a "liberalização da ação empresarial com ou sem o respaldo em leis que não só flexibilizaram o uso da força de trabalho, mas também favoreceram a fraude e a fuga ao cumprimento das normas e das já limitadas obrigações trabalhistas" (THÉBAUD-MONY; DRUCK, 2007, p. 43), lembremos, por exemplo, o Projeto de Lei 4.330/2004 da terceirização aprovado pela Câmara de Deputados em 15/04/15, a qual significa, conforme análise da Associação Nacional dos Magistrados da Justiça do Trabalho (ANAMATRA):

[...] redução de custos, o que na prática tem implicado cortes de despesas com direitos trabalhistas. A realidade demonstra, então, que a terceirização de serviços funciona como mecanismo de diminuição de garantias e de direitos para boa parte dos empregados terceirizados, os quais recebem salários mais baixos e tem menos benefícios quando comparados com trabalhadores da mesma função que não sejam terceirizados. [...] A terceirização comprovadamente também diminui a disponibilidade de postos de empregos e paralelamente aumenta a rotatividade de mão de obra, pontos que são absolutamente prejudiciais não só à classe trabalhadora, mas também a toda a sociedade (ANAMATRA, 2015).

No que tange à precarização, Alves (2009, p. 189) afirma que essa experiência no Brasil decorre da "síndrome objetiva da insegurança de classe (insegurança de 
emprego, de representação, de contrato etc.) que emerge numa textura histórica específica-a temporalidade neoliberal". Tal experiência, conforme o autor é "elemento compositivo do novo metabolismo social que emerge a partir da constituição do Estado neoliberal".

A precarização, segundo o autor fundamenta-se na "intensificação (e a ampliação) da exploração (e a espoliação) da força de trabalho e o desmonte de coletivos de trabalho e de resistência sindical-corporativa" (ALVES, 2009, p.189), bem como na fragmentação social e aumento do desemprego, exercendo pressão sobre a organização dos trabalhadores, os quais perdem SUAS referências de luta coletiva.

As mudanças contemporâneas afetam o mundo do trabalho, como também provocam redefinições profundas no Estado e nas políticas sociais.

As políticas sociais expressam as contradições e os antagonismos das relações entre as classes e destas com o Estado (MOTA, 1995). No capitalismo atual estão cada vez mais submetidas aos ditames da política econômica, "redimensionada(s) ante as tendências de privatização, de cortes nos gastos públicos para programas sociais, focalizados no atendimento à pobreza e descentralizados em sua aplicação" (IAMAMOTO, 2008, p. 147) e com o processo de precarização/flexibilização das condições de trabalho dos agentes que prestam serviços públicos aos usuários das políticas sociais.

Essas mudanças decorrentes da nova etapa da acumulação capitalista atravessam diferentes dimensões da vida social, afetam as relações e gestão do trabalho, "imprimem novas racionalidades às formas de organização do Estado, das políticas públicas e dos sistemas de proteção social, alterando os critérios de distribuição do fundo público e, em consequência, modelando as formas de organização e prestação dos serviços sociais públicos" (RAICHELIS, 2013, p. 611).

$\mathrm{Na}$ análise lúcida de Behring (2008) longe do sentido de solidariedade, pacto social, reforma democrática e redistributivista vividas na perspectiva beveridgeana e socialdemocrata de seguridade, as políticas sociais no escopo da crise do capital, instituem-se a partir de critérios cada vez mais seletivos e focalizados para o atendimento aos direitos sociais. Trata-se de um processo de assistencialização das políticas sociais - funcional à modernização conservadora em curso. 
As políticas governamentais contemporâneas são "favorecedoras da esfera financeira e do grande capital produtivo das instituições e mercados financeiros e empresas multinacionais enquanto forças que capturam o Estado" (IAMAMOTO, 2009, p. 31), redimensionando "a questão social", "radicalizando SUAS expressões", agravando as condições de vida e trabalho dos trabalhadores em geral.

Nessa direção, a lógica orientadora das Políticas Sociais em geral e particularmente da política de assistência social, "fundamentam-se, para a força de trabalho que as executam, com fortes traços e tendências de precarização, focalização e descentralização "(ALENCAR; GRANEMANN, 2009, p.166).

A partir dessa breve contextualização da crise do capital e seus impactos na Política Social, passa-se agora a refletir sobre o trabalho do Assistente Social no âmbito da Política de Assistência Social, à qual, desde a aprovação da Lei Orgânica da Assistência Social (LOAS) em 1993, da Política Nacional de Assistência Social (PNAS) em 2004 e do Sistema Único de Assistência Social (SUAS) em 2005, expressa um conjunto de contradições, pois ao mesmo tempo em que se constitui em conquista para a área da assistência social - historicamente foi vista como não-direito, com a construção de mecanismos de organização, profissionalização e financiamento da política, de outro, efetiva-se por meio de terceirizações e precarização do trabalho dos trabalhadores sociais.

Cabe lembrar que a inserção da Assistência Social no tripé da Seguridade Social ${ }^{1}$ pressupõe, conforme Silveira (2009), compreendê-la em uma perspectiva ampla, democrática, pública, redistributiva e com serviços de qualidade articulando o direito socioassistencial aos demais direitos de proteção social, além de "reformas estruturantes para o enfrentamento das desigualdades e as garantias do trabalho". Pressupõe, conforme a autora, a necessidade de construção e da universalização de direitos e políticas públicas de proteção social, ainda que se reconheçam as contradições que atravessam a Seguridade Social.

\footnotetext{
1 "A definição da Seguridade Social como conceito organizador da proteção social brasileira foi uma das mais relevantes inovações do texto constitucional de 1988. A Constituição Federal (CF) ampliou a cobertura do sistema previdenciário e flexibilizou o acesso aos benefícios para os trabalhadores rurais, reconheceu a Assistência Social como política pública não contributiva que opera tanto serviços como benefícios monetários. [...] a Seguridade Social articulando as políticas de seguro social, assistência social, saúde e seguro-desemprego passa a estar fundada em um conjunto de políticas com vocação universal". (DELGADO; JACCOUD; NOGUEIRA, 2009, p. 17).
} 
Bochetti (2005) por sua vez afirma que a efetivação da Assistência Social como política de Seguridade demanda entendê-la não apenas como uma política exclusiva de proteção social, mas articular seus serviços e benefícios aos direitos assegurados pelas demais políticas sociais, a fim de estabelecer, no âmbito da seguridade social, um amplo sistema de proteção social.

A Política de Assistência Social guardada em sua especificidade não atende de forma exclusiva as demandas e necessidades de seus usuários porque permeada por contradições inerentes ao modo de produção capitalista, para o qual é funcional.

Mota (2008, p. 141) chama atenção para a capacidade de as classes dominantes capitalizarem politicamente a Assistência Social, "transformando-a no principal instrumento de enfrentamento da crescente pauperização relativa, ampliando o exército industrial de reserva no seio das classes trabalhadoras". Vejamos o que acontece com as (os) Assistentes Sociais:

Ao tratar do trabalho do assistente social uma primeira questão desponta para situar o escopo da reflexão desenvolvida nesse texto: o Assistente Social é um trabalhador assalariado, razão pela qual, conforme lamamoto (2007, p. 430) "as dimensões desse trabalho realizam-se por mediações distintas em função da forma assumida pelo valor-capital e pelos rendimentos". Estas mesmas formas, explica a autora, "condicionam, sob a ótica do valor, a contribuição desse trabalhador ao processo de produção e reprodução das relações sociais sob a égide das finanças"

No contexto contemporâneo alteram-se as demandas de trabalho do Assistente Social, modifica-se o mercado de trabalho, alteram-se as condições em que este trabalho se realiza.

O assistente social como trabalhador assalariado, experimenta em seu cotidiano profissional, tanto no setor privado, como no público, mudanças nas condições e relações de trabalho às quais se apresentam precarizadas, entendendo a precarização como um processo de mudança na qualidade das condições de trabalho, evidenciada no capitalismo, com a passagem da forma de produção fordista para a produção flexível.

A precarização, portanto, na ordem contemporânea, se refere às más condições de trabalho, a ausência e/ou redução dos direitos trabalhistas, ao desemprego que 
assola grande parte da população, à fragilidade dos vínculos de trabalho (CAVALCANTE; PRÉDES, 2010).

Na Política de Assistência Social essa realidade cada vez mais se intensifica: pesquisas realizadas por estudiosos da área (ALENCAR; GRANEMANN, 2009; MIOTO; NOGUEIRA, 2013; RAICHELIS, 2010; CAVALCANTE; PRÉDES, 2010; BRISOLA; SILVA, 2014; SANTOS; MANFROI, 2012; SANTOS, 2010), bem como estudos realizados pelo próprio governo federal Ministério de Desenvolvimento Social (MDS) apontam para o processo de precarização das condições de trabalho dos profissionais da área no que tange ao tipo de vínculos, apesar da expansão de postos de trabalho para os assistentes sociais confirmadas pelos Censos SUAS/2014/2013/2012: em 2014 atuavam na política de assistência social 17.567 assistentes sociais nos CRAS; 5420 nos CREAS; 599 nos Centro Pop; 4789 nas Unidades de Acolhimento, perfazendo um total de 28.375 profissionais. No ano de 2013 no CRAS 25.203 e em 2012, 24. 087.

Importante ressaltar que de maneira geral, os trabalhadores do SUAS encontram-se em situação de precarização no que tange ao tipo de vínculos, conforme os dados apontados no Censo /SUAS /2014:

Tabela 1 - Percentual de profissionais ${ }^{2}$ lotados em unidades públicas e privadas que ofertam serviços socioassistenciais segundo o tipo de vínculo - 2014.

\begin{tabular}{lccccc}
\hline Tipos de vínculos & $\begin{array}{c}\text { CRAS } \\
\%\end{array}$ & $\begin{array}{c}\text { CREAS } \\
\%\end{array}$ & $\begin{array}{c}\text { CENTRO POP } \\
\%\end{array}$ & $\begin{array}{c}\text { UNIDADES DE } \\
\text { ACOLHIMENTO } \\
\%\end{array}$ & $\begin{array}{c}\text { CENTROS DE } \\
\text { CONVIVÊNCIA } \\
\%\end{array}$ \\
\hline Outros & 53,4 & 47,8 & 48,4 & 44,0 & 40,7 \\
Comissionados & 9,9 & 8,8 & 6,4 & 3,3 & 4,1 \\
Celetista & 6,8 & 7,5 & 8,2 & 39,9 & 46,1 \\
Estatutários & 29,9 & 35,9 & 37,0 & 12,8 & 9,3 \\
\hline
\end{tabular}

Fonte: Brasil (2014). Dados organizados pela autora.

Os dados acima citados podem indicar também o processo de terceirização dos serviços socioassistenciais, sobretudo nas Unidades de Acolhimento e Centros de Convivência com contratações pela CLT (38,9\% e 46,1\% respectivamente). Por outro lado, há fragilização de vínculos nas unidades estatais (CRAS E CREAS), na medida em

\footnotetext{
${ }^{2}$ Os dados não especificam as categorias profissionais.
} 
que os percentuais de "outros tipos de vínculos" " é alto: 53,4\% para o CRAS; 47.8 para o CREAS; $48,4 \%$ para o Centro Pop; $44,0 \%$ para as Unidades de acolhimento e $40,7 \%$ para os centros de Convivência.

Os dados encontrados em nossas pesquisas na região do Vale do Paraíba ${ }^{4}$ são a expressão exata da realidade mais ampla, com a terceirização dos serviços socioassistenciais, a exemplo dos dados do Censo SUAS $2012^{5}$, segundo o qual nesse ano $35,5 \%$ dos profissionais que atuavam no SUAS eram estatutários; $7,2 \%$ eram contratados em regime CLT; 14,2\% possuíam outro vínculo não permanente; $31,6 \%$ eram temporários; 8,7\% comissionados; e 5,4\% eram terceirizados (BRASIL, 2013). Excetuando-se os estatutários e somando-se os percentuais de trabalhadores com outro tipo de vínculo, tem-se que $67,1 \%$ dos profissionais do SUAS não eram servidores públicos.

Os dados coletados na primeira etapa da pesquisa na Rede SUAS $^{6}$ em 2012 evidenciaram que na, hoje, Região Metropolitana do Vale do Paraíba e Litoral Norte de São Paulo (RMVP-LN) atuavam 370 profissionais nos Centro de Referência de Assistência Social (CRAS) e nos Centro de Referência Especializado de Assistência Social (CREAS), dos quais 238 (64.3\%) são assistentes sociais e os demais se dividem entre psicólogos, advogados, pedagogos e outras profissões de nível superior.

Verificou-se também que, dos trabalhadores sociais que atuam no SUAS, cerca de 111 (30\%) são estatutários, ou seja, são servidores públicos municipais, aprovados em concurso; 177 (50\%) são contratos pelo regime da Consolidação das Leis Trabalhistas (CLT); 29 (7,8\%) são temporários; 21 (5,6\%) são comissionados, ou seja, cargos de indicação política; 10 (2,7\%) são cooperados; 15 (4,0\%) possuem outro vínculo não especificado e $7(1,8 \%)$ não possuem vínculo empregatício de qualquer natureza (são, possivelmente, autônomos [RPAs] e/ou voluntários).

\footnotetext{
${ }^{3}$ No Censo SUAS há explicitação acerca do significado de "outros", " como consultores, servidores cedidos por outros órgãos públicos, terceirizados, estagiários" (BRASIL, 2013, p. 67).

${ }^{4}$ Referimo-nos à pesquisa financiada pelo CNPq "O trabalho do Assistente Social no SUAS: entre novos desafios e velhos dilemas" realizada na região metropolitana do Vale do Paraíba e Litoral Norte entre 2011-2014, sob nossa coordenação. Os dados da pesquisa encontram-se sistematizados e publicados no livro "O trabalho do Assistente Social no SUAS: entre velhos dilemas e novos desafios", publicado em 2014 pela Cabral Editora

${ }^{5} \mathrm{O}$ Censo SUAS abarca dados de todas as regiões do Brasil.

${ }^{6}$ Disponível para consulta no site: http://aplicacoes.mds.gov.br/cadsuas/visualizarConsultaExterna.html.
} 
A Tabela 2 abaixo explicita o número de trabalhadores sociais e seus respectivos vínculos empregatícios por município da Região Metropolitana do Vale do Paraíba e Litoral Norte:

Tabela 2 - Número de trabalhadores conforme o Vínculo Empregatício por município da Região Metropolitana do Vale do Paraíba e Litoral Norte.

\begin{tabular}{|c|c|c|c|c|c|c|c|c|}
\hline 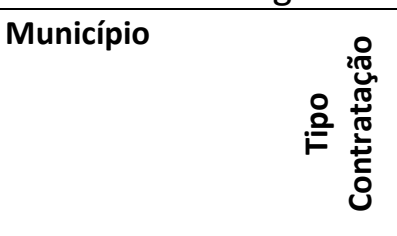 & 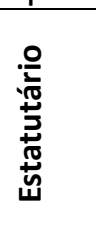 & こ & 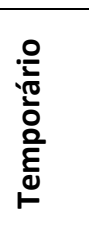 & $\begin{array}{l}\frac{0}{0} \\
\frac{\pi}{0} \\
\frac{0}{0} \\
\frac{0}{\varepsilon} \\
\stackrel{0}{0}\end{array}$ & $\begin{array}{l}\circ \\
\frac{0}{\pi} \\
\frac{\pi}{0} \\
\frac{0}{0} \\
0\end{array}$ & 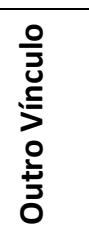 & 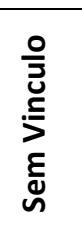 & 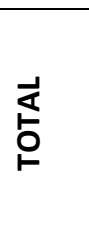 \\
\hline Aparecida & 1 & 2 & 6 & 1 & - & - & - & 10 \\
\hline Areias & - & 4 & - & - & - & - & - & 4 \\
\hline Bananal & - & 1 & - & 2 & - & - & - & 3 \\
\hline Caçapava & - & 2 & - & 1 & - & - & - & 3 \\
\hline Cachoeira Paulista & - & 4 & - & 1 & - & 1 & - & 6 \\
\hline Campos do Jordão & - & 3 & - & - & - & - & - & 3 \\
\hline Canas & 2 & - & - & 2 & - & - & - & 4 \\
\hline Caraguatatuba & 8 & 6 & 21 & 5 & - & 11 & 1 & 52 \\
\hline Cruzeiro & 1 & 2 & - & 1 & - & - & - & 4 \\
\hline Cunha & - & 3 & - & - & - & - & - & 3 \\
\hline Guaratinguetá & - & 23 & - & - & - & - & - & 23 \\
\hline Ilhabela & 6 & - & - & 1 & - & - & - & 7 \\
\hline Jacareí & 35 & - & - & - & - & - & - & 35 \\
\hline Jambeiro & 1 & 2 & - & - & - & - & - & 3 \\
\hline Lagoinha & - & 2 & - & - & - & - & - & 2 \\
\hline Lavrinhas & - & 5 & - & 1 & - & - & - & 6 \\
\hline Lorena & 11 & - & - & 2 & - & - & 1 & 14 \\
\hline Pindamonhangaba & - & 24 & - & - & - & - & - & 24 \\
\hline Piquete & - & 3 & - & - & - & - & - & 3 \\
\hline Potim & 1 & - & 1 & - & - & - & - & 2 \\
\hline Queluz & - & 3 & - & - & - & - & - & 3 \\
\hline Roseira & 3 & - & - & 1 & - & - & - & 4 \\
\hline Santa Branca & - & 4 & - & - & - & - & - & 4 \\
\hline Santo Antônio do Pinhal & - & 4 & - & - & - & - & - & 4 \\
\hline São Bento do Sapucaí & - & 1 & - & - & - & - & - & 1 \\
\hline São José do Barreiro & - & 4 & 1 & - & - & 1 & - & 6 \\
\hline São José dos Campos & 26 & 65 & - & 1 & 9 & - & 1 & 102 \\
\hline São Luís do Paraitinga & - & 2 & - & 1 & - & - & - & 3 \\
\hline São Sebastião & 13 & - & - & - & - & - & - & 13 \\
\hline Silveiras & - & 4 & - & - & - & - & - & 4 \\
\hline Taubaté & 2 & 3 & - & - & - & - & 2 & 7 \\
\hline Tremembé & - & - & - & - & - & 2 & 2 & 4 \\
\hline Ubatuba & 1 & 1 & - & 1 & 1 & - & - & 4 \\
\hline TOTAL & 111 & 177 & 29 & 21 & 10 & 15 & 7 & 370 \\
\hline
\end{tabular}

Fonte: Rede SUAS, 2012. Dados organizados pela autora.

Nos dados apresentados pelo Censo SUAS/2014 essa tendência permanece, visto que em 2010, eram 36,6\% de profissionais estatutários no Brasil; em 2011, 34,0\%; no ano de 2012, 35,5\%; em 2013, 35,8\% e em 2014 35,1\%. Em contrapartida, 
tem-se em 2014 o aumento de profissionais com "outros vínculos" alcançado o maior percentual da série histórica analisada, 37\%; 16,9\% comissionados; $11 \%$ celetistas.

O Censo SUAS/2014 ainda traz um dado que merece análise: do conjunto de profissionais que atuam no SUAS a maior concentração se dá no nível médio no CRAS com 23.934, contra 9.507 psicólogos, 5.690 pedagogos, 7.705 outras formações e 26.038 sem formação. Também se registra a expansão de trabalhadores de nível médio no CREAS (1004) e no Centro Pop (952).

A constatação da realidade dos trabalhadores do SUAS quanto ao tipo de contratação remete à seguinte questão: "a não obediência dos direitos trabalhistas nos vínculos de trabalho configura a supressão do acesso à proteção social do próprio trabalhador" (NERY, 2009, p. 96) e, nessa perspectiva, pergunta-se como um trabalhador sem direitos irá defender os direitos do outro. Por outro lado, entende-se que a composição das equipes de referência por meio de concursos públicos que atestem o conhecimento técnico e científico dos profissionais, "confere estabilidade do ponto de vista trabalhista" e "é parte fundamental do processo de construção de uma política pública de Estado" (FERREIRA, 2009, p. 110).

A precarização das condições de contratação e, consequentemente, de trabalho dos profissionais que atuam no SUAS não garante continuidade dos trabalhadores em SUAS funções e, na maioria das vezes, as contratações são em tempo parcial (10 ou 20 horas semanais) e/ou por prazo determinado, por projetos ou cooperativas. Entretanto, uma das diretrizes da Norma Operacional Básica de Recursos Humanos (NOB-RH/SUAS) é que "a gestão do trabalho no âmbito do SUAS deva garantir a formalização dos vínculos dos trabalhadores do SUAS e o fim da terceirização, além de garantir a educação permanente dos trabalhadores" (BRASIL, 2013, p. 7).

Exemplo desse processo é verificado também no Estado de Santa Catarina conforme estudos de Santos e Manfroi (2012), revelando um percentual importante de assistentes sociais que trabalham, não apenas em mais de um projeto no âmbito das organizações sociais prestadoras de serviços socioassistenciais, mas também profissionais que atuam em dois a três municípios, em razão de baixos salários.

As pesquisas realizadas em Alagoas por Prédes e Cavalcante (2010) sobre o mercado de trabalho do serviço social, apontam para a mesma lógica, ou seja, foi 
"constatado que embora haja uma ampliação da inserção dos assistentes sociais no mercado de trabalho no âmbito do setor público, os profissionais vivenciam diversos.

Aspectos de um trabalho precarizado. Principalmente devido às condições precárias em que se encontram os serviços públicos em todas as esferas de governo, implicando na redução de profissionais e na escassez de recursos financeiros, devido aos ajustes neoliberais".

Esse processo de precarização do trabalho socioassistencial é gerador de inúmeras dificuldades tanto para os profissionais que atuam na área quanto para os usuários da política, visto que a "mercadorização" (ANTUNES, 2007) dos serviços socioassistenciais, têm se expressado como desresponsabilização estatal e adoção da cultura gerencial característica da chamada flexibilização produtiva, a qual visa à racionalização e intensificação dos ritmos e processos de trabalho, transferindo a execução dos serviços para organizações sociais "filantrópicas", frequentemente vinculadas a instituições religiosas.

A terceirização dos serviços socioassistenciais "desconfigura o significado e a amplitude do trabalho técnico realizado pelos assistentes sociais e demais trabalhadores sociais", além de deslocar "as relações entre a população, SUAS formas de representação e gestão governamental, pela intermediação de empresas e organizações sociais" (RAICHELIS, 2009, p. 384).

A autora ainda aponta que a terceirização dos serviços socioassistenciais opera uma cisão entre serviço e direito, na medida em que "a lógica que preside o trabalho não é pública, obscurecendo-se a responsabilidade do Estado perante seus cidadãos" (RAICHELIS, 2009, p. 384).

A terceirização dos serviços socioassistenciais e a contratação precária de profissionais assumem, conforme Raichelis (2010), características específicas na Assistência Social, considerando o seu histórico de desprofissionalização e descontinuidade das ações. Ao que parece, a política vive uma espécie de retorno ao passado no que concerne à parceria público-privado, visto que historicamente as organizações sociais compuseram o quadro dessa política. Evidentemente, as bases dessa nova lógica se diferenciam daquelas do passado, porém os efeitos deletérios continuam presentes tanto para os usuários da política, como para os profissionais. 
A pesquisa, base dessa análise, identificou as principais dificuldades que os profissionais enfrentam ao trabalhar no campo do SUAS, quais sejam: falta de estabilidade; insegurança no trabalho; precarização das condições de trabalho; aumento do trabalho com exigências de cumprimento de metas; burocratização, baixos salários, ausência de capacitações, dentre outras.

Analisar, portanto, o trabalho do Assistente Social no SUAS demanda a identificação das contradições do fazer profissional como trabalhador assalariado que atua no âmbito das políticas e não dispõe dos recursos para sua ação e, nessa condição, Ihe são impostos "parâmetros institucionais e trabalhistas que regulam as relações de trabalho", os quais "condicionam o conteúdo do trabalho realizado e estabelecem limites e possibilidades à realização dos propósitos profissionais" (IAMAMOTO, 2009, p. 38).

\begin{abstract}
A condição assalariada do exercício profissional pressupõe a mediação do mercado de trabalho. Assim, as exigências impostas pelos distintos empregadores materializam demandas, estabelecem funções e atribuições, impõem regulamentações específicas a serem empreendidos no âmbito do trabalho coletivo (CEOLIN, 2014, p.241).
\end{abstract}

No âmbito das instituições empregadoras, o assistente social integra o trabalho coletivo para a implementação de ações determinadas pelas instituições, logo, o resultado de seu trabalho depende, dentre outros aspectos, "do prévio recorte das políticas definidas pelos organismos empregadores, que estabelecem demandas e prioridades a serem atendidas" (IAMAMOTO, 2007, p. 421), o que, certamente, contribui para a diminuição da autonomia profissional. Silva (2012, p. 156) confirma essa lógica ao afirmar que a:

Política de Assistência Social impacta diretamente o cotidiano profissional,
tensionando as dimensões das competências e atribuições privativas do
assistente social que postula um profissional crítico vinculado às demandas
coletivas de usuários, ao acesso aos direitos, e as demandas institucionais
que vêm exigindo um profissional com um perfil mais tecnicista, cuja
tendência é de fortalecimento das bases conservadoras do Serviço Social, e,
portanto, de mero controle de parcelas da classe trabalhadora usuária desta
política.

Em artigo publicado por Raichelis (2013) acerca dos impactos da crise mundial sobre o Sistema de Proteção Social e o trabalho do assistente Social, os achados da autora corroboram com as vivências dos profissionais entrevistados na pesquisa que 
serve de base nesse texto, explicitando que no contexto da precarização há um excessivo aumento de "trabalho", aumento esse funcional à despolitização, visto que os profissionais dedicam-se ao trabalho burocrático, "com o preenchimento de formulários e planilhas padronizadas, a multiplicação das visitas domiciliares para fins de controle institucional das provisões e prestações sociais, a realização de cadastramentos da população", ou seja, cada vez mais os assistentes sociais dedicamse a tarefas que não permitem a reflexão, rebaixando a qualidade e importância de seu trabalho, além de não permitir a articulação com os usuários da política (RAICHELIS. 2013, p. 624).

A burocracia, nesse sentido, assume lugar de destaque nas práticas profissionais, ocultando o sentido do fazer profissional, impondo uma racionalidade de tipo novo, a qual inibe a reflexão crítica e as possibilidades de resistência dos profissionais, que estão trabalhando cada vez mais.

Conforme Raichelis (2013) na conjuntura contemporânea além da intensificação do trabalho, as exigências são cada vez maiores assim como as cobranças de resultados quantitativos em detrimento dos qualitativos, com evidente "degradação e exploração do trabalho, em outros termos, a adoção de estratégias de redução do trabalho pago e ampliação do trabalho excedente, o que está na raiz do sofrimento do trabalhador assalariado" (RAICHELIS, 2013, p. 623).

Nesse sentido, a precarização é idelogicamente funcional ao novo modelo de gestão do trabalho, na medida em que permite a emergência da "racionalidade" nova do capital e, ao mesmo tempo, subtrai dos trabalhadores o tempo necessário para sua organização política, articulação com movimentos sociais e usuários, seja pelo excesso de trabalho que os mobiliza no ambiente laboral, seja pelo esgotamento físico provocado por esse excesso ${ }^{7}$. Cabe lembrar que a redução do tempo de trabalho propiciada pela "flexibilização" representada pelo emprego em tempo parcial, temporário, autônomo e informal - não corresponde ao aumento do tempo livre possivelmente destinado à organização política dos trabalhadores -, já que a

\footnotetext{
7 Há importantes estudos sobre a função ideológica da precarização do trabalho estável e formal. Ver, entre outros, Antunes (2005, 2007) e Organista (2006); e sobre o adoecimento profissional ver Seligmann-Silva (2012).
} 
diminuição das jornadas significa, geralmente, a "redução dos salários, obrigando as pessoas a multiplicar SUAS ocupações" (ORGANISTA, 2006, p. 68).

Do ponto de vista da gestão do trabalho, os profissionais apontam para a nova racionalidade do Estado que passa a reordenar e regulamentar as prestações de serviços com o intuito de evitar supostos desperdícios e a racionalizar o trabalho visando a "eficiência" e a "eficácia" nos moldes gerenciais. A adoção da lógica ou da linguagem do capital (RAICHELIS, 2010) gera, no mínimo, o esvaziamento do espaço público como arena de disputas de interesses antagônicos, convertendo-se, em um espaço despolitizado.

Os profissionais, por seu turno, ressentem-se de espaços para expor SUAS ideias e experiências na medida em que o planejamento não passa por essa instância. Aos profissionais é delegada apenas a função executora. Tal perspectiva produz, no limite, desânimo (e, em alguns casos, desistência dissimulada) no que se refere ao potencial emancipatório do projeto profissional do Serviço Social.

Outro elemento derivado da precarização das condições de trabalho se refere ao processo de despolitização da categoria. Conforme Antunes (2007, p. 22) na "nova morfologia do trabalho", a classe trabalhadora é mais fragmentada, heterogênea e complexificada, consequentemente, mais despolitizada.

As narrativas dos profissionais entrevistados, ou melhor, no silêncio desses, observa-se distância no que se refere à participação nos organismos da categoria (conjunto CFESS/CRESS); movimentos sociais, sindicatos ou partidos, os quais se constituem mecanismos de fortalecimento da luta pelos direitos socioassistenciais, bem como pelos direitos dos trabalhadores em geral.

Dos profissionais entrevistados somente um destaca a importância do diálogo constante com os organismos da categoria como forma de enfrentamento dos desafios postos à profissão:

Acredito que o conjunto CFESS/CRESS, apesar de alguns problemas existentes, ainda assim são canais legítimos de discussão e fortalecimento da categoria. Basta à gente participar (AS. de município de Grande Porte/Organização Social). 
Identifica-se, nessa perspectiva, um processo de despolitização no interior da assistência social, na medida em que os profissionais estão submersos à rotina do trabalho:

[...] o trabalho é extremamente burocratizado, não temos tempo para mais nada (AS. de município de Médio Porte).

[...] nós não temos momentos para nos reunir e refletir sobre o próprio trabalho, sobre as nossas condições de trabalho (AS. Município de Porte Grande).

[...] A gente trabalha em muitas frentes, às vezes com três projetos. Aí, a gente não dá conta de mais nada (AS de Organização social conveniada com município Porte Grande).

Como adverte Antunes (2007, p. 22) a reversão desse processo se dará por meio de "um novo desenho das formas de representação das forças sociais".

\section{Considerações finais}

Como foi possível apontar nessa reflexão, o assistente social como trabalhador é impactado, assim como os demais trabalhadores, pelas estratégias e táticas perversas do capital com vistas à recomposição de SUAS taxas de lucro.

Nessa direção, evidenciam-se novos desafios postos aos profissionais na medida em que os processos de terceirização, flexibibilização e precarização atingem o campo das políticas sociais públicas, restringindo o poder de negociação dos trabalhadores, exponenciando o trabalho e reduzindo os direitos conquistados por meio de lutas sociais. As mudanças ocorridas na dinâmica do trabalho atingem os profissionais em geral por sua condição de assalariamento.

Especificamente, no caso dos Assistentes Sociais, a insegurança gerada por contratos precários, associada ao acúmulo de trabalho cada vez mais burocrático inibe a organização dos profissionais, levando-os a sofrimentos tanto físicos como emocionais e a enfrentamentos de caráter individual de questões afetas ao coletivo. De outro lado, as condições precárias de trabalho afetam a qualidade do trabalho desenvolvido junto à população usuária dos serviços socioassistenciais, comprometendo o projeto profissional do Serviço Social.

O processo de precarização que atinge a todos "é um processo que mina as formas de resistência e luta dos trabalhadores, disseminando a (falsa) ideia de 
fatalidade econômica e irreversibilidade política da situação presente" (RAICHELIS, 2013, p. 618).

O contexto contemporâneo, portanto, conforme Berhing (2008) aponta a necessidade de associar coragem e racionalidade para o enfrentamento dos processos em curso nesse período regressivo, contrarrevolucionário e contra reformista, de falta de nitidez dos projetos societários e confusão dos espíritos, e diríamos de superexploração da força de trabalho, de precarização das condições de trabalho e vida, de desregulamentação dos direitos conquistados pela classe trabalhadora, de barbárie.

No que se refere aos assistentes sociais, impõe-se cada vez a necessidade de articulação com outros profissionais, usuários, sindicatos e partidos de forma a fortalecer o projeto democrático e os direitos das classes trabalhadoras.

Por outro lado, conforme Mota (2014, p. 700) a problematização das "expressões cotidianas e imediatas da realidade e que se constituem em demandas às instituições e ao Serviço Social [pode] levar o profissional exercitar uma relativa autonomia intelectual que oriente SUAS propostas de intervenção com base nas condições objetivas existentes".

Da mesma maneira, a participação nos organismos da categoria, é estratégica para a resistência coletiva.

Assim, apesar das contradições identificadas na realidade social, não podemos perder de vista as possibilidades de resistência e enfrentamento coletivo. Em tempos tão sombrios, cabe o fortalecimento e defesa do projeto ético-político do serviço social, contra a superexploração da força de trabalho.

\section{Referências}

ALENCAR, M. M. T. de; GRANEMANN, Ofensiva do capital e novas determinações do trabalho profissional. Revista Katálysis, Florianópolis, v. 12, n. 2, p. 161-169, jul./dez. 2009. Disponível em: <http://www.scielo.br/pdf/rk/v12n2/05.pdf>. Acesso em: 8 Abr. 2014.

ALVES, G. Trabalho e reestruturação produtiva no Brasil neoliberal - Precarização do trabalho e redundância salarial. Revista Katáysis, Florianópolis, v. 12, n. 2, p. 188-197, jul./dez. 2009. Disponível em: <http://www.scielo.br/pdf/rk/v12n2/08 .pdf>. Acesso em: 1 abr. 2014. 
ANAMATRA - Associação dos Magistrados da Justiça do Trabalho. Diga não à terceirização e à precarização no trabalho. Disponível em:

<http://www.anamatra.org.br/index.php/>. Acesso em: 28 maio 2015.

ANTUNES, R. Dimensões da precarização estrutural do trabalho. In: DRUCK, G;

FRANCO, T. (Org.). A perda da razão social do trabalho. Terceirização e Precarização.

São Paulo: Boitempo Editorial, 2007. p. 13-22.

ANTUNES, R. O caracol e sua concha: ensaios sobre a nova morfologia do trabalho. São Paulo: Boitempo, 2005.

BEHRING, E. Acumulação capitalista, fundo público e política social. In. BOSCHETTI, I. et al. (Org.). Política Social no Capitalismo: Tendências Contemporâneas. São Paulo: Cortez, 2008.

BOSCHETTI, I. O SUAS e a Seguridade Social. In: CONFERÊNCIA NACIONAL DE ASSISTÊNCIA SOCIAL, 5., Brasília, 2005. Cadernos de Estudos. Desenvolvimento Social em Debate, n. 2. Disponível em: <http://www.rnpd.org.br/download/publicacoes/ Textos_para_V_Conferencia_Nacional_de_Assistencia_Social.pdf >. Acesso em: 21 Jun. 2016.

BRASIL. Ministério do Desenvolvimento Social e Combate à fome. Censo SUAS, 2012. Disponível em: <http://aplicacoes.mds.gov.br/sagirmps/ferramentas/docs/censo/ CensoSUAS_2012_final.pdf>. Acesso em: 4 Fev. 2014.

BRASIL. Ministério do Desenvolvimento Social e Combate à fome. Censo SUAS, 2013. Disponível em: <http://www.mds.gov.br/webarquivos/publicacao/assistencia_social/ Livros/CensoSUAS_2013.pdf>. Acesso em: 20 Jun. 2016.

BRASIL, Ministério do Desenvolvimento Social e Combate à fome. Censo SUAS, 2014. Disponível em: <https://issuu.com/sagi_mds/docs/censo_SUAS_2014>. Acesso em: 20 Jun. 2016.

BRISOLA, E. M. A; SILVA, A. L. O trabalho do assistente social no SUAS: novos desafios e velhos dilemas. In: BRISOLA, E. M. A; SILVA, A. L. (Org.). O trabalho do assistente social no SUAS. Taubaté-SP: Cabral Editora e Livraria Universitária, 2014.

CAVALCANTE, G.M. M; PRÉDES, R. A precarização do trabalho e das políticas sociais na sociedade capitalista: fundamentos da precarização do trabalho do assistente social. Libertas, Juiz de Fora, v.10, n.1, p. 1-24, jan-jun., 2010.

CEOLIN, G. F. Crise do capital, precarização do trabalho e impactos no Serviço Social. Serviço Social \& Sociedade, São Paulo, n. 118, p. 239-264, abr./jun. 2014. Disponível em: <www.scielo.br/pdf/sssoc/n118/a03n118.pdf>. Acesso em: 14 Jun. 2015.

DELGADO, G; JACCOUD, L; NOGUEIRA, R.P. Seguridade Social: redefinindo o alcance da cidadania. Seguridade Social, Brasília, n 17, v. 1, p. 17-40, 2009. Disponível em: http://repositorio.ipea.gov.br/bitstream/11058/4347/1/bps_n17_vol01_seguridade _social.pdf>. Acesso em: 14 Jun. 2015. 
FERREIRA, S. da S. A construção do lugar dos trabalhadores do Sistema único de Assistência Social: uma análise da Norma Operacional Básica Recursos Humanos. 2009. Dissertação (Mestrado em Serviço Social) - Pontifícia Universidade Católica-SP, São Paulo, 2009.

IAMAMOTO, M.V. O Serviço Social na cena contemporânea. In: CONSELHO FEDERAL DE SERVIÇO SOCIAL. Serviço Social: direitos sociais e competências profissionais. Brasília: CFESS/ABEPSS, 2009. p. 15-50.

. Estado, classes trabalhadoras e política social no Brasil. In: BOSCHETTI, I. et al. (Org.). Política Social no Capitalismo: Tendências Contemporâneas. São Paulo: Cortez, 2008.

Serviço Social em tempo de capital fetiche: Capital financeiro, trabalho e questão social. São Paulo: Cortez, 2007.

MÉSZÁROS, I. O desafio e o fardo do tempo histórico. Tradução Ana Cotrim e Vera Cotrim. São Paulo: Boitempo, 2007.

. Para além do capital. Tradução Paulo César Castanheira e Sérgio Lessa. São Paulo: Unicamp, Boitempo, 2002.

MOTA, A. E. Espaços ocupacionais e dimensões políticas da prática do assistente social. Serviço Social \& Sociedade, São Paulo, n. 120, p. 694-705, out./dez. 2014. Disponível em: <www.scielo.br/pdf/sssoc/n120/06.pdf>. Acesso em: 14 Jun. 2015.

- Redução da pobreza e aumento da desigualdade: um desafio teórico-político ao serviço Social brasileiro. MOTA, A. E. (Org.). As ideologias da contrarreforma e o Serviço Social. Recife: Ed. Universitária da UFPE, 2010.

Cultura de crise e seguridade social: um estudo sobre as tendências da previdência e da assistência social brasileira nos anos 80 e 90.4 ed. São Paulo: Cortez, 1995.

MIOTO, R. C. T; NOGUEIRA, V. M. R. Política Social e Serviço Social: os desafios da intervenção profissional. Revista Katálysis, Florianópolis, v. 16, n. esp., p. 61-71, 2013. Disponível em: <http://www.scielo.br/pdf/rk/v16nspe/05.pdf>. Acesso em: $8 \mathrm{Abr}$. 2014.

NERY, V. B. O trabalho dos assistentes sociais e psicólogos na política de Assistência Social: saberes e direitos em questão. 2009. Tese (Doutorado em Serviço Social) Pontifícia Universidade Católica-SP, São Paulo, 2009.

ORGANISTA, J. H. C. O debate sobre a centralidade do trabalho. São Paulo: Expressão Popular, 2006.

RAICHELIS, R. Proteção social e trabalho do assistente social: tendências e disputas na conjuntura de crise mundial. Serviço Social \& Sociedade, São Paulo, n. 116, p. 609-635, 
out./dez. 2013. Disponível em: <http://www.scielo.br/pdf/sssoc/n116/03.pdf>. Acesso em: 10 jan. 2014.

. Intervenção profissional do assistente social e as condições de trabalho no

SUAS. Serviço Social \& Sociedade, São Paulo, n. 104, p. 750-772, out/dez. 2010.

Disponível em: <http://www.scielo.br/pdf/sssoc/n104/10.pdf>. Acesso em: 12 mar. 2011.

. O trabalho do assistente social na esfera estatal. In: CONSELHO FEDERAL DE SERVIÇO SOCIAL. Serviço Social: direitos sociais e competências profissionais. Brasília: CFESS/ABEPSS, 2009. p. 378-391.

SANTOS, M. B, J. dos. O trabalho do assistente social no SUAS: relações de trabalho e competências profissionais. In: MOTA, A. E. (Org.). As ideologias da contrarreforma e o Serviço Social. Recife: Ed. Universitária da UFPE, 2010.

SANTOS, M.T; MANFROI, V. M. Expansão e Precarização: O mercado de trabalho dos assistentes sociais em Santa Catarina. Em Pauta, Rio de Janeiro, n. 30, v. 10, p. 233252, 2오. Sem., 2012.

SILVA, J. A. F. Serviço Social e Sistema Único de Assistência Social (SUAS): reflexões sobre o trabalho profissional. Ser Social, Brasília, v. 14, n. 30, p. 155-189, jan./jun. 2012. Disponível em: <http://periodicos.unb.br/index.php/SER_Social/article/ viewFile/ 7443/ 5751>. Acesso em: 3 abr. 2014.

SILVEIRA, J. I. Sistema Único de Assistência Social: institucionalidade e processos interventivos. Serviço Social \& Sociedade, São Paulo, n. 98, p. 335-361, abr/jun, 2009.

SILVA-DELIGMANN, E. Trabalho e desgaste mental. O direito de ser dono de si. São Paulo: Cortez, 2011.

THÉBAUD-MONY, A.; DRUCK, G. Terceirização: a erosão dos direitos dos trabalhadores na França e no Brasil. In. DRUCK, G; FRANCO, T. (Org.). A perda da razão social do trabalho: Terceirização e Precarização. São Paulo: Boitempo Editorial, 2007. p. 23-58. 